\title{
Association analysis between agronomic traits and AFLP markers in a wide germplasm of proso millet (Panicum miliaceum L.) under normal and salinity stress conditions
}

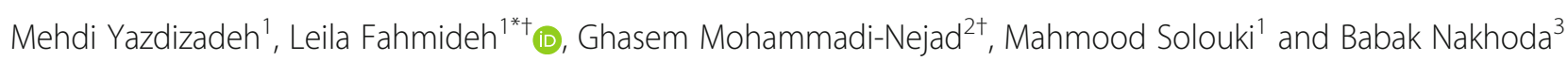

\begin{abstract}
Background: Proso millet is a highly nutritious cereal considered an essential component of processed foods. It is also recognized with high water-use efficiency as well as short growing seasons. This research was primarily aimed at investigating the genetic diversity among genotypes based on evaluating those important traits proposed in previous researches under both normal and salinity- stress conditions. Use of Amplified fragment length polymorphism (AFLP) molecular markers as well as evaluating the association between markers and the investigated traits under both conditions was also another purpose of this research.

Results: According to the phenotypic correlation coefficients, the seed yield had the highest correlation with the forage and biological yields under both conditions. By disintegrating those traits investigated under normal and salinity-stress conditions into principal component analysis, it was found that the first four principal components justified more than 59.94 and $62.48 \%$ of the whole variance, respectively. The dendrogram obtained by cluster analysis displayed three groups of genotypes under both normal and salinity- stress conditions. Then, association analyses were conducted on 143 proso millet genotypes and 15 agronomic traits as well as 514 polymorphic AFLP markers (out of 866 created bands) generated by 11 primer combinations (out of the initial 20 primer combinations) EcoRI/Msel. The results obtained by mixed linear model (MLM) indicated that under normal conditions, the M14/E10-45 and M14/E10-60 markers had strong associations with seed yield. A similar trend was also observed for M14/E10-45 and M14/E11-44 markers in relation to forage yield. On the other hand, M14/E10-14, M14/E10-64 markers (for seed yield) and M14/E10-64 marker (for forage yield), had significant and stable association in all environments under salinity-stress conditions. Moreover, a number of markers showed considerable associations and stability under both normal and salinity stress conditions.

(Continued on next page)
\end{abstract}

\footnotetext{
* Correspondence: I.fahmideh@uoz.ac.ir

${ }^{\dagger}$ Leila Fahmideh and Ghasem Mohammadi-Nejad contributed equally to this work.

'Department of Plant Breeding and Biotechnology, Faculty of Agriculture, University of Zabol, Zabol, Sistan and Baluchestan province, Iran Full list of author information is available at the end of the article
}

(c) The Author(s). 2020 Open Access This article is licensed under a Creative Commons Attribution 4.0 International License, which permits use, sharing, adaptation, distribution and reproduction in any medium or format, as long as you give appropriate credit to the original author(s) and the source, provide a link to the Creative Commons licence, and indicate if changes were made. The images or other third party material in this article are included in the article's Creative Commons licence, unless indicated otherwise in a credit line to the material. If material is not included in the article's Creative Commons licence and your intended use is not permitted by statutory regulation or exceeds the permitted use, you will need to obtain permission directly from the copyright holder. To view a copy of this licence, visit http://creativecommons.org/licenses/by/4.0/. The Creative Commons Public Domain Dedication waiver (http://creativecommons.org/publicdomain/zero/1.0/) applies to the data made available in this article, unless otherwise stated in a credit line to the data. 
(Continued from previous page)

Conclusions: According to the analysis of phenotypic data, the wide germplasm of Iranian proso millet has significant variation in terms of measured traits. It can be concluded that markers showing strong associations with traits under salinity-stress conditions are suitable candidates to be used in future marker-assisted selection (MAS) studies to improve salinity-resistance genotypes of Panicum miliaceum in arid and semiarid areas.

Keywords: Amplified fragment length polymorphism, Genetic linkage, Population structure, MLM model, Marker stability

\section{Background}

The genus proso millet (Panicum miliaceum L.), belongs to the Paniceae family in the Panicoideae subfamily. As an ancient grain crop, its historical reports date back to 10,000 years ago and has been the major cultivated grain crop in Europe since 2000 [1]. Today, it is produced in Eastern Europe, Russia, China, India, and North America [2-4]. Millet is one of those crops with the shortest growth periods (60-90 days) compared to other cereals. Moreover, its drought-resistance and hot spring forage plant makes it adaptable to challenging environmental conditions. It is also a low-maintenance and stressresistant plant producing acceptable yield, making it appropriate for crop production in inhospitable climates [5-7]. Furthermore, it contains special alkaline proteins and a relatively balanced array of rare elements and vitamin precursors that exceed the levels in products such as wheat, rice and barley. Therefore, millet has remained an important component of the human diet [7-9].

Water-related impacts including climate change effects, namely water scarcity, increased agricultural land salinity, heightened intensity and longer drought periods as well as rising need for plant products led to further investigation into agriculture under saline conditions in countries like Iran [10-14]. Salinity stress causes a wide range of reactions in plants. Change in gene expression and cell metabolism, variation in plant growth rates and yields, reduction in the biomass production and efficiency of photosynthesis as well as altering leaf turgidity are among the main consequences of salinity stress [15].

Along with ever-increasing use of modified substances inside germplasm with the purpose of developing plants, the methods employed for classification and management of genetic diversity have received increasing attention. In this context, using statistical multi-variable approaches is considered an important strategy in germplasm classification, managing diversity among a large number of samples as well as evaluating the genetic associations in those investigated substances [16-19]. Cluster analysis, as one of multi-variable methods and initially employed to classify members based on their respective traits is used to mathematically organize individuals in a specific cluster. In this method, those members held in a cluster have the highest similarity or uniformity. This is while the highest level of difference or non-uniformity is observed between separate clusters. Therefore, those members inside a cluster would genetically be closer to each other while clusters with higher differences would have further distances in a diagram [20]. A cluster is assumed acceptable if i) a group of two or more genotypes has a within-cluster genetic distance of less than that of the overall mean ii) the genetic distance between two clusters is greater than that of within- cluster distance. Principal component analysis is one of the main characteristics of multi-variable approaches. This method, also used as a technique to reduce data into a limited number of non- associated variables, is employed to better understand the relationships among two or more traits. Furthermore, it can be employed to realize the differences among members and identify probable groups [21]. Identifying correlation among yields is an effective tool to determine valuable genotypes. High correlation and an acceptable heritability are essential criteria to select a trait for breeding programs [22]. To this end, practical statistics are appropriate approaches to determine the associations among genetic markers and phenotypic data via Genome-wide association study (GWAS). Therefore, such approaches increasingly facilitate use of genetic resources to improve yields [23].

Since phenotype is influenced by the environment, molecular methods such as DNA marker procedure are effective in molecular description of complicated traits [24]. It is noteworthy that DNA-based markers are the most appropriate methods to estimate genetic variation. Furthermore, markers which exhibit higher levels of diversity will have higher efficiency. The AFLP method not only needs background knowledge on the targeted genome but also has high reproducibility and sensitivity for finding polymorphism at various levels of the DNA sequence while provides valuable information in various loci of the targeted genome. Thus, the AFLP markers have been used in molecular and genetic studies in recent years $[25,26]$. Kumar et al. [26] reported that AFLP is an indicator of genetic categorization, manufacturing of linkage maps, mapping of essential agronomic traits and devoting parentage. 
Association analysis is extensively adopted to explore and identify relationships among molecular markers and agronomic traits based on linkage disequilibrium (LD) [27]. The accuracy of linkage analysis is influenced by many factors such as the magnitude of polymorphism between two parents, the population size, the distribution of chiasma in a genome and the time needed to produce artificial populations. Nevertheless, association analysis does not require pure populations. Besides, natural populations are used to find associations between markers and traits in this method. By establishing the recombination of these populations, the relationship between the markers and the traits would be accurate and reliable $[28,29]$.

Association analysis is performed using both general linear model (GLM) and mixed linear model (MLM) [30]. In GLM model, the marker is considered a constant variable and causes the first type to be incorrect. Therefore, a fake association is formed between the marker and trait. These types of errors are partly resolved using the $\mathrm{Q}$ matrix derived from the structure of the population. This matrix expresses the probable rate based on which each element can be attributed to the sub-structures. It also prevents incorrect associations between traits and markers which in turn greatly reduces type-1 error [26, 30, 31]. Meanwhile, both factors are used in MLM model by combining $\mathrm{Q}$ and $\mathrm{K}$ matrices to obtain more power compared to linear modeling. The $\mathrm{K}$ matrix expresses the kinship association of individuals in the population [32]. In order to evaluate the DNA polymorphism and genetic diversity among three domestic and nine wild proso millet biotypes, eight primer combinations and 39 polymorphic DNA fragments were identified [33, 34]. Le Thierry d' Ennequin et al. [35] found that AFLP markers could be used to evaluate the genetic association between foxtail millet and green foxtail. Colosi and Shaal [36] also used the random amplified polymorphic DNA (RAPD) marker to evaluate the genetic diversity among 97 species including 69 wild proso millets, 26 crops and crop-like weeds as well as two hybrid genotypes. Rajput et al. [37] performed association analysis using 548 SSR markers. Their study led to the identification of 339 polymorphics in 8 proso millet genotypes. Ebrahimi et al. [38] performed association analysis on eight important traits and 341 polymorphic AFLP markers produced by 10 primer combinations (EcoRI/MseI) among 100 safflower genotypes.

Little investigation has been carried out on the association analysis of proso millet agronomic traits using a large number of markers. The association analysis of proso millet agronomic traits is performed using AFLP as a molecular marker. This study involves a significant number of ecotypes under both normal and salinitystress conditions. Use of this approach might be useful to improve the efficiency of marker-assisted selection and other breeding projects. The targets of the present study are: (i) investigating the genetic diversity among genotypes based on evaluation of those important traits proposed in previous researches under normal and salinity- stress conditions; (ii) evaluation of population genetic structures to detect essential marker-trait associations of the genotypes; (iii) the effectiveness of AFLPs in recognizing the loci marker association with significant agronomic traits of Iranian species subjected to normal and salinity-stress conditions, separately; and (iv) determining the stability of respective loci markers with the desired agronomic traits corresponding to both conditions.

\section{Results}

\section{Analysis of phenotypic data}

Analysis of variance (ANOVA) was performed through the PROC ANOVA procedure of SAS 9.1. The results indicated that genotypes had significant differences in terms of all agronomic traits under both normal and salinity-stress conditions. Moreover, all traits except panicle length were considerably influenced by the environment as well as the genotype $\times$ environment interaction in all conditions (Additional file 1: Table S1). This implied a significant genetic variation in terms of traits and the possible selection and application of these traits in breeding programs.

Salinity stress reduced seed and forage yield by 20 and $12 \%$, respectively. Regarding the investigated traits, proso millet cultivars had an extensive phenotypic variation. For example, the genotype G57 had the highest average percentage of seed germination while it had the lowest mean value for the number of tillers.

Under normal conditions, the highest quantities of seed and forage yields were determined 2.94 t/ha (G32) and $6.35 \mathrm{t} / \mathrm{ha}$ (G32), respectively. In addition, the lowest quantities were reported $1.56 \mathrm{t} / \mathrm{ha}$ (G141) and $3.35 \mathrm{t} / \mathrm{ha}$ (G141), respectively. Under salinitystress conditions, the highest quantities of seed and forage yield were estimated $3.05 \mathrm{t} / \mathrm{ha}$ (G44) and $7 \mathrm{t} / \mathrm{ha}$ (G142) while the lowest quantities were reported 0.52 t/ha (G63) and $0.78 \mathrm{t} / \mathrm{ha}$ (G18), respectively (data not shown). The evaluated broad-sense heritability (h2) required to measure the traits of proso millet genotypes are given in Additional file 1: Table S1. The highest h2 value was observed in the 1000 -seed weight $(0.97$ and 0.96 under normal and salinitystress conditions, respectively) while the lowest $h^{2}$ value was estimated for plant height $(0.55$ and 0.27 under normal and salinity-stress conditions, respectively) (Additional file 1: Table S1). 


\section{Correlation coefficients analysis}

According to the phenotypic correlation coefficients, the seed and forage yields had positive and significant correlations with all investigated traits except for the number of leaves, flag leaf length, flag leaf width and panicle length under normal conditions Moreover, the seed yield had the highest correlations with forage and biological yields as well as the seed germination percentage (Table 1). This is while the forage yield had the highest correlations with seed and biological yields as well as the seed germination percentage.

Under salinity-stress conditions, the seed yield demonstrated positive and significant correlations with all traits except for flag leaf width and panicle length. Moreover, the seed yield had the highest correlations with biological and forage yields as well as the main panicle seeds weight. This is while the forage yield demonstrated the highest correlations with biological and seed yields as well as the panicle seeds weight under similar conditions. Besides, the forage yield had no significant correlations with flag leaf width, panicle length and harvest index (Table 2).

\section{Principal component analysis}

By disintegrating those traits investigated under normal conditions into principal component analysis and taking into account the eigenvalues of larger than unity; it was found that the first four principal components justified more than $59.94 \%$ of the whole variance. Furthermore, the first, second, third and fourth components constituted $31.22,11.91,8.94$ and $7.87 \%$ of the whole variance, respectively (Table 3). The seed germination, seed yield as well as forage and biological yields had the highest coefficients in the first principal component. Moreover, the first principal component demonstrated positive correlations with the above mentioned traits. Therefore, determining genotypes with the highest values of the first principal component could lead to the identification of those with the highest potential yields under normal conditions. The panicle length, flag leaf width, number of panicle branches, 1000-seed weight and harvest index had the highest coefficients in the second principal component (Table 4). Therefore, this principal component, having smaller share in variance compared to the first one, would have stronger correlations with growth and reproductive properties to produce seeds. The positive and significant correlations of these traits with the second principal component indicated that those genotypes with higher values of the second principal component would have greater growth and reproduction capability. The plant height, number of leaves, number of tillers, number of panicle branches and number of plants on the line and 1000-seed weight had the highest positive coefficients in the third principal component (Table 4). This is while the plant height, flag leaf length and harvest index justified the most variance of the forthprincipal component. Therefore, those genotypes with the highest values of the third and fourth principal components would have more such traits (Table 5).

By disintegrating, those traits investigated under salinity-stress conditions into principal component analysis and taking into account the eigenvalues of larger than unity; it was found that the first four principal components justified more than $62.48 \%$ of the whole

Table 1 Phenotypic correlation coefficients of investigated traits of proso millet genotypes under normal conditions

\begin{tabular}{|c|c|c|c|c|c|c|c|c|c|c|c|c|c|c|c|}
\hline Code of traits & 1 & 2 & 3 & 4 & 5 & 6 & 7 & 8 & 9 & 10 & 11 & 12 & 13 & 14 & 15 \\
\hline 1 & 1 & & & & & & & & & & & & & & \\
\hline 2 & $0.25^{* *}$ & 1 & & & & & & & & & & & & & \\
\hline 3 & $0.13^{\mathrm{ns}}$ & $0.14^{\mathrm{ns}}$ & 1 & & & & & & & & & & & & \\
\hline 4 & $0.15^{\mathrm{ns}}$ & $0.22^{* *}$ & $0.14^{\mathrm{ns}}$ & 1 & & & & & & & & & & & \\
\hline 5 & $0.08^{\text {ns }}$ & $0.50^{\mathrm{ns}}$ & $-0.13^{\mathrm{ns}}$ & $0.15^{\mathrm{ns}}$ & 1 & & & & & & & & & & \\
\hline 6 & $0.30^{* *}$ & $0.20^{* *}$ & $0.15^{\mathrm{ns}}$ & $0.02^{\text {ns }}$ & $0.01^{\mathrm{ns}}$ & 1 & & & & & & & & & \\
\hline 7 & $0.05^{\mathrm{ns}}$ & $0.04^{\mathrm{ns}}$ & $0.07^{\mathrm{ns}}$ & $0.08^{\mathrm{ns}}$ & $0.36^{* *}$ & $0.04^{\mathrm{ns}}$ & 1 & & & & & & & & \\
\hline 8 & $0.71^{* *}$ & $0.38^{* *}$ & $0.13^{\mathrm{ns}}$ & $0.12^{\mathrm{ns}}$ & $0.05^{\text {ns }}$ & $0.31^{* *}$ & $0.12^{\mathrm{ns}}$ & 1 & & & & & & & \\
\hline 9 & $0.29 * *$ & $0.25^{* *}$ & $0.01^{* *}$ & $0.16^{*}$ & $0.12^{\mathrm{ns}}$ & $0.22^{* *}$ & $0.19^{*}$ & $0.26^{* *}$ & 1 & & & & & & \\
\hline 10 & $0.31^{* *}$ & $0.26^{* *}$ & $-0.03^{\text {ns }}$ & $0.13^{\mathrm{ns}}$ & $0.12^{* *}$ & $0.34^{* *}$ & $0.04^{\text {ns }}$ & $0.28^{* *}$ & $0.30^{* *}$ & 1 & & & & & \\
\hline 11 & $0.11^{* *}$ & $0.39^{* *}$ & $0.13^{\mathrm{ns}}$ & $0.12^{\mathrm{ns}}$ & $0.05^{\mathrm{ns}}$ & $0.31^{* *}$ & $0.12^{\mathrm{ns}}$ & $0.99^{* *}$ & $0.26^{* *}$ & $0.28^{* *}$ & 1 & & & & \\
\hline 12 & $0.17^{*}$ & $0.05^{\mathrm{ns}}$ & $-0.04^{\mathrm{ns}}$ & $0.15^{\mathrm{ns}}$ & $0.13^{\text {ns }}$ & $0.07^{\mathrm{ns}}$ & $0.27^{* *}$ & $0.23^{* *}$ & $0.08^{\mathrm{ns}}$ & $0.09^{\text {ns }}$ & $0.22^{* *}$ & 1 & & & \\
\hline 13 & $0.28^{* *}$ & $0.33^{* *}$ & ${ }^{\text {ns }} 06.0$ & $0.19^{* *}$ & $0.13^{\text {ns }}$ & $0.20^{*}$ & $0.20^{*}$ & $0.30^{* *}$ & $0.31^{* *}$ & $0.28^{* *}$ & $0.30^{* *}$ & $0.23^{* *}$ & 1 & & \\
\hline 14 & $-0.27^{* *}$ & $-0.21^{* *}$ & $-0.14^{\mathrm{ns}}$ & $0.16^{\mathrm{ns}}$ & $0.07^{\mathrm{ns}}$ & $-0.27^{\mathrm{ns}}$ & $-0.09^{\mathrm{ns}}$ & $-0.21^{*}$ & $-0.05^{\mathrm{ns}}$ & $-0.04^{\mathrm{ns}}$ & $-0.23^{*}$ & $0.23^{* *}$ & $-0.12^{\mathrm{ns}}$ & 1 & \\
\hline 15 & $0.72^{* *}$ & $0.39^{* *}$ & $0.13^{\mathrm{ns}}$ & $0.12^{\mathrm{ns}}$ & $0.05^{\mathrm{ns}}$ & $0.31^{* *}$ & $0.12^{\mathrm{ns}}$ & $0.99^{* *}$ & $0.26^{* *}$ & $0.28^{* *}$ & $0.99 * *$ & $0.22^{* *}$ & $0.30^{* *}$ & $-0.20^{* *}$ & 1 \\
\hline
\end{tabular}

$\mathrm{ns},{ }^{*}, * *$ not significant, significant at 0.05 and 0.01 level, respectively 
Table 2 Phenotypic correlation coefficients of investigated traits of proso millet genotypes under salinity stress conditions

\begin{tabular}{|c|c|c|c|c|c|c|c|c|c|c|c|c|c|c|c|}
\hline Code of traits & 1 & 2 & 3 & 4 & 5 & 6 & 7 & 8 & 9 & 10 & 11 & 12 & 13 & 14 & 15 \\
\hline 1 & 1 & & & & & & & & & & & & & & \\
\hline 2 & $* * 340$. & 1 & & & & & & & & & & & & & \\
\hline 3 & $* 170$. & ns 110. & 1 & & & & & & & & & & & & \\
\hline 4 & *180. & $* * 380$. & ${ }^{\text {ns }} 050$. & 1 & & & & & & & & & & & \\
\hline 5 & ${ }^{\text {ns }} 060$. & ${ }^{\text {ns }} 140$. & ${ }^{\text {ns } 130 .-}$ & ${ }^{\mathrm{ns}} 120$. & 1 & & & & & & & & & & \\
\hline 6 & $* * 270$. & $* * 310$. & $* * 190$. & $* * 270$. & ${ }^{\text {ns }} 060$. & 1 & & & & & & & & & \\
\hline 7 & ns 0050. & ns 0740. & ${ }^{\text {ns } 130 .-}$ & ns030. & $0.30^{* *}$ & ${ }^{* *} 030$ & 1 & & & & & & & & \\
\hline 8 & $0.05^{* *}$ & $* * 430$. & $* 170$. & $* * 220$. & ${ }^{\text {ns }} 060$. & **580. & ${ }^{\mathrm{ns}} 140$. & 1 & & & & & & & \\
\hline 9 & $* * 240$. & $* * 470$. & ${ }^{\text {ns }} 070$. & ${ }^{*} 160$. & ${ }^{\text {ns }} 140$. & $* * 320$. & *190. & $* * 460$ & 1 & & & & & & \\
\hline 10 & $* * 450$. & $* * 290$. & ${ }^{\text {ns }} 030$. & ${ }^{* *} 020$. & ${ }^{\text {ns }} 140$. & $* * 350$. & ${ }^{\mathrm{ns}} 020$. & $* * 490$. & $* * 370$ & 1 & & & & & \\
\hline 11 & $* * 450$. & $* * 420$. & *170. & $* * 280$ & ${ }^{\text {ns }} 060$. & $0.60^{* *}$ & ns 140. & $* * 850$. & $* * 360$. & $* * 430$. & 1 & & & & \\
\hline 12 & $* * 270$ & $* * 230$. & ${ }^{\text {ns }} 040$. & $0.10^{\mathrm{ns}}$ & ${ }^{\text {ns }} 080$. & ${ }^{\mathrm{ns}} 070$. & $* * 210$. & $* * 650$. & $* * 240$. & $* * 290$. & $0.50^{* *}$ & 1 & & & \\
\hline 13 & ${ }^{* *} 0.28$ & **310. & ${ }^{\mathrm{ns}} 070$ & $* * 29 /$ & ns 130. & $* * 220$ & ${ }^{* *} 020$. & $0.50^{* *}$ & $* * 240$. & $0.40^{* *}$ & $* * 490$ & $* * 050$ & 1 & & \\
\hline 14 & $* * 190$. & ${ }^{\text {ns }} 060$. & ${ }^{\text {ns }} 030 .-$ & ${ }^{\text {ns }} 080 .-$ & ${ }^{\text {ns }} 060 .-$ & ${ }^{\text {ns }} 070$. & ${ }^{\mathrm{ns}} 020$. & $* * 310$ & ${ }^{\text {ns }} 090$. & ${ }^{n s} 130$. & ns $180 .-$ & $* * 350$. & ns 110. & 1 & \\
\hline 15 & $* * 480$. & $* * 440$. & ${ }^{*} 170$. & $* * 270$. & ns 060. & **610. & ns 150. & $0.93^{* *}$ & $0.39 * *$ & $0.46^{* *}$ & $0.98^{* *}$ & $0.57^{* *}$ & $0.52^{* *}$ & $0.05^{\mathrm{ns}}$ & 1 \\
\hline
\end{tabular}

$\mathrm{ns},{ }^{*}, * *$ not significant, significant at 0.05 and 0.01 level, respectively

variance. Moreover, the first, second, third and fourth components constituted 35.79, 9.96, 9.50 and $7.23 \%$ of the whole variance, respectively. According to the results, seed germination, plant height, number of tillers, seed and forage yields along with 1000 seed-weight justified the highest variance of the first principal component (Table 6). As seen, these traits were more related with the capacity of plants to have higher yields under stress conditions. Therefore, this principal component could be described as yield potential. Moreover, a positive correlation was found between yield and this principal

Table 3 The principal component values of proso millet genotypes under normal conditions

\begin{tabular}{llll}
\hline Number of PCA & Eigenvalue & Variability (\%) & Cumulative \% \\
\hline $\mathbf{1}$ & 4.68 & 31.22 & 31.22 \\
$\mathbf{2}$ & 1.79 & 11.91 & 43.13 \\
$\mathbf{3}$ & 1.34 & 8.94 & 52.07 \\
$\mathbf{4}$ & 1.18 & 7.87 & 59.94 \\
$\mathbf{5}$ & 0.98 & 6.54 & 66.49 \\
$\mathbf{6}$ & 0.93 & 6.22 & 72.71 \\
$\mathbf{7}$ & 0.78 & 5.23 & 77.94 \\
$\mathbf{8}$ & 0.71 & 4.70 & 82.64 \\
$\mathbf{9}$ & 0.68 & 4.55 & 87.19 \\
$\mathbf{1 0}$ & 0.60 & 3.97 & 91.16 \\
$\mathbf{1 1}$ & 0.53 & 3.50 & 94.66 \\
$\mathbf{1 2}$ & 0.49 & 3.26 & 97.92 \\
$\mathbf{1 3}$ & 0.30 & 2.07 & 99.99 \\
$\mathbf{1 4}$ & 0.01 & 0.01 & 100.00 \\
\hline
\end{tabular}

component (Table 7). Hence, selecting those genotypes with higher values of the first principal component would facilitate identifying those genotypes with higher yield potentials under stress conditions. Since leaf width, panicle length and number of tillers justified the highest portion of variance in the second principal component, this principal component could probably express the capacity of genotypes to assign extra photosynthesized materials to seeds production. Furthermore, flag leaf

Table 4 Members constituting the first five components based on investigated traits of proso millet genotypes under normal conditions

\begin{tabular}{llllll}
\hline Code of traits & PCA 1 & PCA 2 & PCA 3 & PCA 4 & PCA 5 \\
\hline $\mathbf{1}$ & 0.37 & -0.09 & -0.12 & -0.01 & -0.10 \\
$\mathbf{2}$ & 0.24 & -0.02 & 0.29 & 0.23 & 0.00 \\
$\mathbf{3}$ & 0.08 & -0.33 & 0.16 & -0.13 & 0.73 \\
$\mathbf{4}$ & 0.10 & 0.31 & 0.00 & 0.57 & -0.09 \\
$\mathbf{5}$ & 0.07 & 0.41 & 0.11 & -0.45 & -0.27 \\
$\mathbf{6}$ & 0.22 & -0.11 & 0.34 & -0.07 & 0.01 \\
$\mathbf{7}$ & 0.10 & 0.44 & 0.03 & -0.47 & 0.08 \\
$\mathbf{8}$ & 0.43 & -0.10 & -0.28 & -0.02 & -0.05 \\
$\mathbf{9}$ & 0.21 & 0.18 & 0.36 & 0.07 & 0.17 \\
$\mathbf{1 0}$ & 0.22 & 0.13 & 0.33 & 0.21 & -0.19 \\
$\mathbf{1 1}$ & 0.43 & -0.11 & -0.27 & -0.03 & -0.06 \\
$\mathbf{1 2}$ & 0.13 & 0.39 & -0.31 & -0.04 & 0.41 \\
$\mathbf{1 3}$ & 0.23 & 0.23 & 0.29 & 0.08 & 0.23 \\
$\mathbf{1 4}$ & -0.15 & 0.35 & -0.33 & 0.33 & 0.26 \\
$\mathbf{1 5}$ & 0.43 & -0.10 & -0.27 & -0.02 & -0.06 \\
\hline
\end{tabular}


Table 5 Correlation of investigated traits with the first five components of proso millet genotypes under normal conditions

\begin{tabular}{llllll}
\hline Code of traits & PCA $\mathbf{1}$ & PCA 2 & PCA 3 & PCA 4 & PCA 5 \\
\hline $\mathbf{1}$ & 0.79 & -0.12 & -0.14 & -0.02 & -0.09 \\
$\mathbf{2}$ & 0.53 & -0.03 & 0.34 & 0.25 & 0.00 \\
$\mathbf{3}$ & 0.18 & -0.43 & 0.19 & -0.15 & 0.72 \\
$\mathbf{4}$ & 0.22 & 0.42 & 0.00 & 0.62 & -0.09 \\
$\mathbf{5}$ & 0.15 & 0.55 & 0.13 & -0.49 & -0.27 \\
$\mathbf{6}$ & 0.47 & -0.15 & 0.40 & -0.08 & 0.01 \\
$\mathbf{7}$ & 0.22 & 0.59 & 0.04 & -0.52 & 0.08 \\
$\mathbf{8}$ & 0.92 & -0.13 & -0.32 & -0.02 & -0.05 \\
$\mathbf{9}$ & 0.45 & 0.24 & 0.42 & 0.08 & 0.17 \\
$\mathbf{1 0}$ & 0.47 & 0.18 & 0.38 & 0.23 & -0.19 \\
$\mathbf{1 1}$ & 0.92 & -0.14 & -0.31 & -0.03 & -0.06 \\
$\mathbf{1 2}$ & 0.29 & 0.53 & -0.35 & -0.04 & 0.41 \\
$\mathbf{1 3}$ & 0.50 & 0.31 & 0.34 & 0.09 & 0.23 \\
$\mathbf{1 4}$ & -0.32 & 0.47 & -0.38 & 0.36 & 0.26 \\
$\mathbf{1 5}$ & 0.92 & -0.14 & -0.31 & -0.03 & -0.06 \\
\hline
\end{tabular}

width and panicle length had the highest values of the third principal component while plant height, number of panicle branches as well as number of plants on the line constituted the highest values of the forth one. Therefore, these principal components would probably indicate the vegetative growth of genotypes. Regarding the highly positive correlations of the above mentioned traits with the second, third and fourth principal components, selecting those genotypes having the highest values of

Table 6 Members constituting the first five components based on investigated traits of proso millet genotypes under salinity

\begin{tabular}{llll} 
stress conditions & & & \\
\hline Number of PCA & Eigenvalue & Variability (\%) & Cumulative \% \\
\hline $\mathbf{1}$ & 5.36 & 35.79 & 35.79 \\
$\mathbf{2}$ & 1.49 & 9.96 & 45.75 \\
$\mathbf{3}$ & 1.42 & 9.50 & 55.25 \\
$\mathbf{4}$ & 1.08 & 7.23 & 62.48 \\
$\mathbf{5}$ & 0.95 & 6.35 & 68.83 \\
$\mathbf{6}$ & 0.88 & 5.84 & 74.67 \\
$\mathbf{7}$ & 0.82 & 5.48 & 80.15 \\
$\mathbf{8}$ & 0.72 & 4.78 & 84.93 \\
$\mathbf{9}$ & 0.64 & 4.27 & 89.20 \\
$\mathbf{1 0}$ & 0.58 & 3.88 & 93.08 \\
$\mathbf{1 1}$ & 0.43 & 2.88 & 95.96 \\
$\mathbf{1 2}$ & 0.39 & 2.57 & 98.53 \\
$\mathbf{1 3}$ & 0.20 & 1.32 & 99.85 \\
$\mathbf{1 4}$ & 0.02 & 0.15 & 100.00 \\
\hline
\end{tabular}

Table 7 Members constituting the first five components based on investigated traits of proso millet genotypes under salinity stress conditions

\begin{tabular}{llllll}
\hline Code of traits & PCA 1 & PCA 2 & PCA 3 & PCA 4 & PCA 5 \\
\hline $\mathbf{1}$ & 0.26 & -0.14 & 0.06 & 0.27 & 0.04 \\
$\mathbf{2}$ & 0.25 & 0.06 & -0.24 & 0.35 & 0.09 \\
$\mathbf{3}$ & 0.07 & -0.44 & -0.10 & -0.12 & -0.21 \\
$\mathbf{4}$ & 0.16 & 0.10 & -0.38 & 0.18 & 0.61 \\
$\mathbf{5}$ & 0.08 & 0.57 & -0.18 & 0.06 & -0.18 \\
$\mathbf{6}$ & 0.27 & -0.17 & -0.26 & 0.01 & -0.34 \\
$\mathbf{7}$ & 0.09 & 0.58 & 0.06 & -0.27 & -0.27 \\
$\mathbf{8}$ & 0.40 & -0.09 & 0.19 & -0.09 & -0.06 \\
$\mathbf{9}$ & 0.24 & 0.13 & -0.14 & 0.35 & -0.39 \\
$\mathbf{1 0}$ & 0.27 & 0.01 & 0.00 & 0.31 & 0.01 \\
$\mathbf{1 1}$ & 0.38 & -0.11 & -0.12 & -0.35 & -0.03 \\
$\mathbf{1 2}$ & 0.27 & 0.12 & 0.45 & -0.19 & 0.19 \\
$\mathbf{1 3}$ & 0.28 & 0.15 & 0.11 & -0.14 & 0.39 \\
$\mathbf{1 4}$ & 0.09 & -0.01 & 0.63 & 0.44 & -0.08 \\
$\mathbf{1 5}$ & 0.40 & -0.10 & -0.02 & -0.27 & -0.04 \\
\hline
\end{tabular}

these principal components is highly recommended (Table 8).

\section{Cluster analysis}

In this research, cluster analysis was used for grouping the lines. Under normal conditions, the tree diagram obtained by cluster analysis displayed three groups of genotypes. The first, second and third clusters were

Table 8 Correlation of investigated traits with the first five components of proso millet genotypes under salinity stress conditions

\begin{tabular}{llllll}
\hline Code of traits & PCA $\mathbf{1}$ & PCA 2 & PCA 3 & PCA 4 & PCA 5 \\
\hline $\mathbf{1}$ & 0.59 & -0.18 & 0.07 & 0.28 & 0.03 \\
$\mathbf{2}$ & 0.59 & 0.07 & -0.29 & 0.37 & 0.08 \\
$\mathbf{3}$ & 0.17 & -0.54 & -0.12 & -0.12 & -0.20 \\
$\mathbf{4}$ & 0.38 & 0.12 & -0.46 & 0.19 & 0.59 \\
$\mathbf{5}$ & 0.18 & 0.69 & -0.22 & 0.06 & -0.17 \\
$\mathbf{6}$ & 0.63 & -0.21 & -0.31 & 0.02 & -0.33 \\
$\mathbf{7}$ & 0.21 & 0.70 & 0.07 & -0.28 & -0.26 \\
$\mathbf{8}$ & 0.92 & -0.11 & 0.22 & -0.09 & -0.06 \\
$\mathbf{9}$ & 0.54 & 0.16 & -0.16 & 0.37 & -0.38 \\
$\mathbf{1 0}$ & 0.62 & 0.01 & 0.00 & 0.32 & 0.01 \\
$\mathbf{1 1}$ & 0.88 & -0.13 & -0.14 & -0.36 & -0.02 \\
$\mathbf{1 2}$ & 0.63 & 0.15 & 0.54 & -0.20 & 0.19 \\
$\mathbf{1 3}$ & 0.64 & 0.18 & 0.13 & -0.15 & 0.38 \\
$\mathbf{1 4}$ & 0.20 & -0.02 & 0.75 & 0.46 & -0.08 \\
$\mathbf{1 5}$ & 0.92 & -0.13 & -0.02 & -0.28 & -0.04 \\
\hline
\end{tabular}


comprised of 54, 38 and 51 genotypes, respectively (Fig. 1) (Additional file 2: Table S2).

Under salinity-stress conditions, the corresponding diagram displayed three groups of genotypes. The first, second and third clusters consisted of 79, 41 and 23 genotypes, respectively (Fig. 2) (Additional file 3: Table S3).

\section{Allele diversity}

In total, 866 bands were created using 11 primer combinations, of which 514 bands were polymorphic. Since small alleles are usually used in LD assessment of pairs of loci [39], those alleles with a frequency of less than 0.05 were deleted before analysis. In this research, the Polymorphic Information Content index (PIC) ranged from 0.13 (M3/E10) to 1.21 (M14/E10) with a mean value of 0.6 . Furthermore, the number of polymorphic bands for each primer combination varied from a minimum value of $12(\mathrm{M} 3 / \mathrm{E} 11)$ to a maximum value of 81 (M14/E10). On the other hand, the lowest polymorphic percentage (22.78\%) was determined for corresponding M3/E10 primer combination. This is while the M14/E10 primer combination had the highest polymorphism of 97.59\%. However, the average value of polymorphism was $58 \%$. Moreover, the highest Shannon index $(\mathrm{H})$ (2.20) was reported for M14/E10 primer combination while the lowest value (0.29) was determined for M3/ E10 primer combination. Nonetheless, the average value of the Shannon index was determined 1.13. The primer combinations M3/E10 and M14/E10 also showed the lowest and highest marker index (MI), respectively (Table 9).

\section{Population structure}

The number of clusters (K) present in proso millet (Panicum miliaceum L.) was determined by structure analysis. The value of $\Delta \mathrm{K}$ was plotted versus the number of subpopulations (K) and structure analysis was subsequently performed based on the method adopted by Evanno et al. [40] The highest value of $\Delta \mathrm{K}$ was observed at $K=5$. According to the results obtained by HARVES TER STRUCTURE, the highest level of $\Delta \mathrm{K}$ corresponded to $\mathrm{K}=$ five. Figures 3,4 and 5 show the four stages used to determine the real value of $\mathrm{K}$ (Table 10).

It was observed that the contribution of the variance among and within the sub-populations were 7 and $93 \%$ of the total variance, respectively (Table 11). Moreover, the analogue stabilization index (PhiPT) values were significant, highlighting considerable genetic variations among subpopulations. On the other hand, the PhiPT values of each pair of subpopulations indicated significant differences among all subpopulations.

\section{Association analysis}

According to the association analysis performed by MLM model, the number of markers showing significant relationship with the average of the investigated traits was determined 67 and 65 under normal and salinitystress conditions, respectively (Additional file 4: Table S4). However, kinship or affinity was not expected as an agent in GLM model. Moreover, the number of considerable markers increased to 93 and 99 under normal and salinity-stress conditions, respectively (data not shown). Based on the results obtained by MLM model, the determination coefficient $\left(R^{2}\right)$ ranged from about 3.28 to

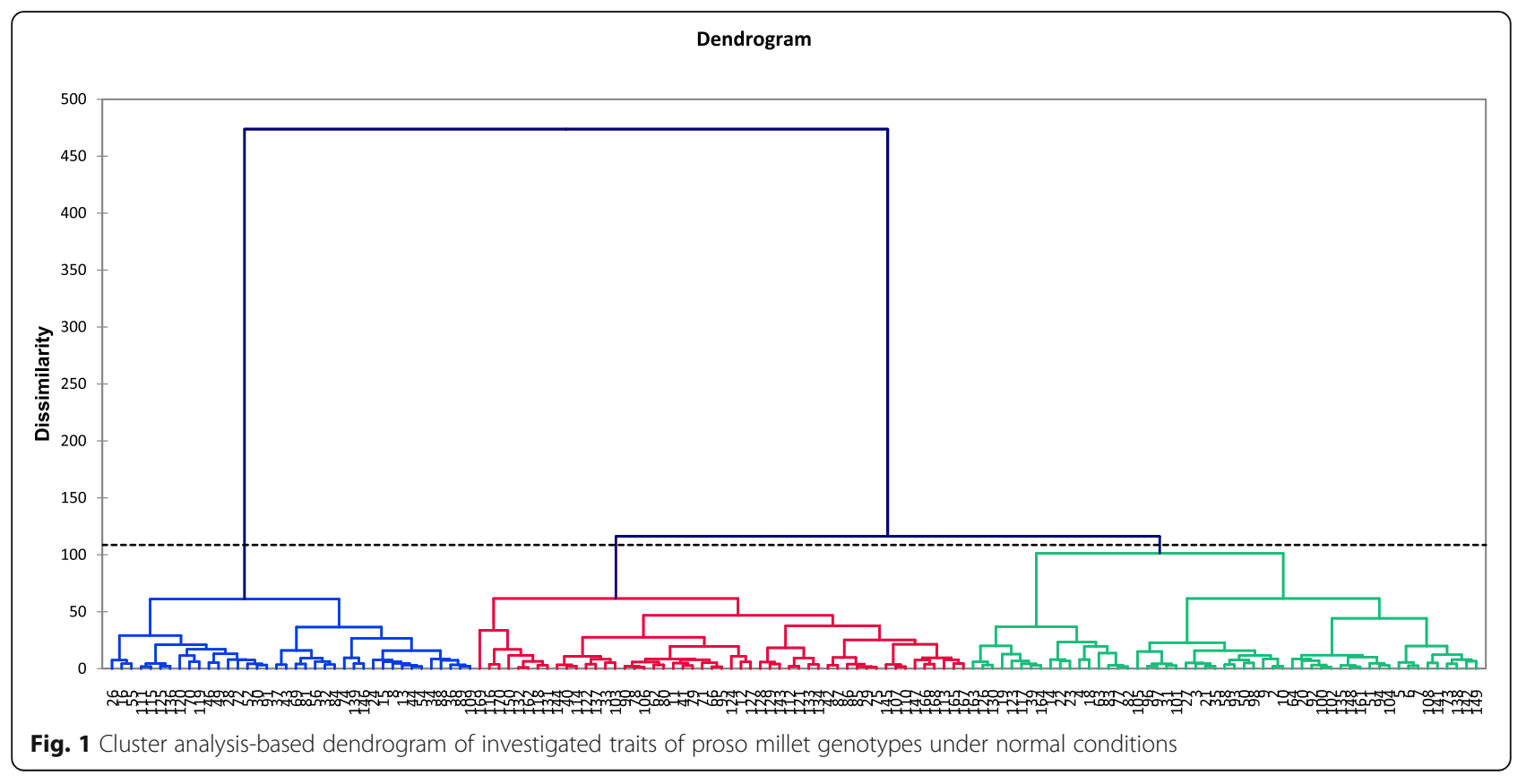




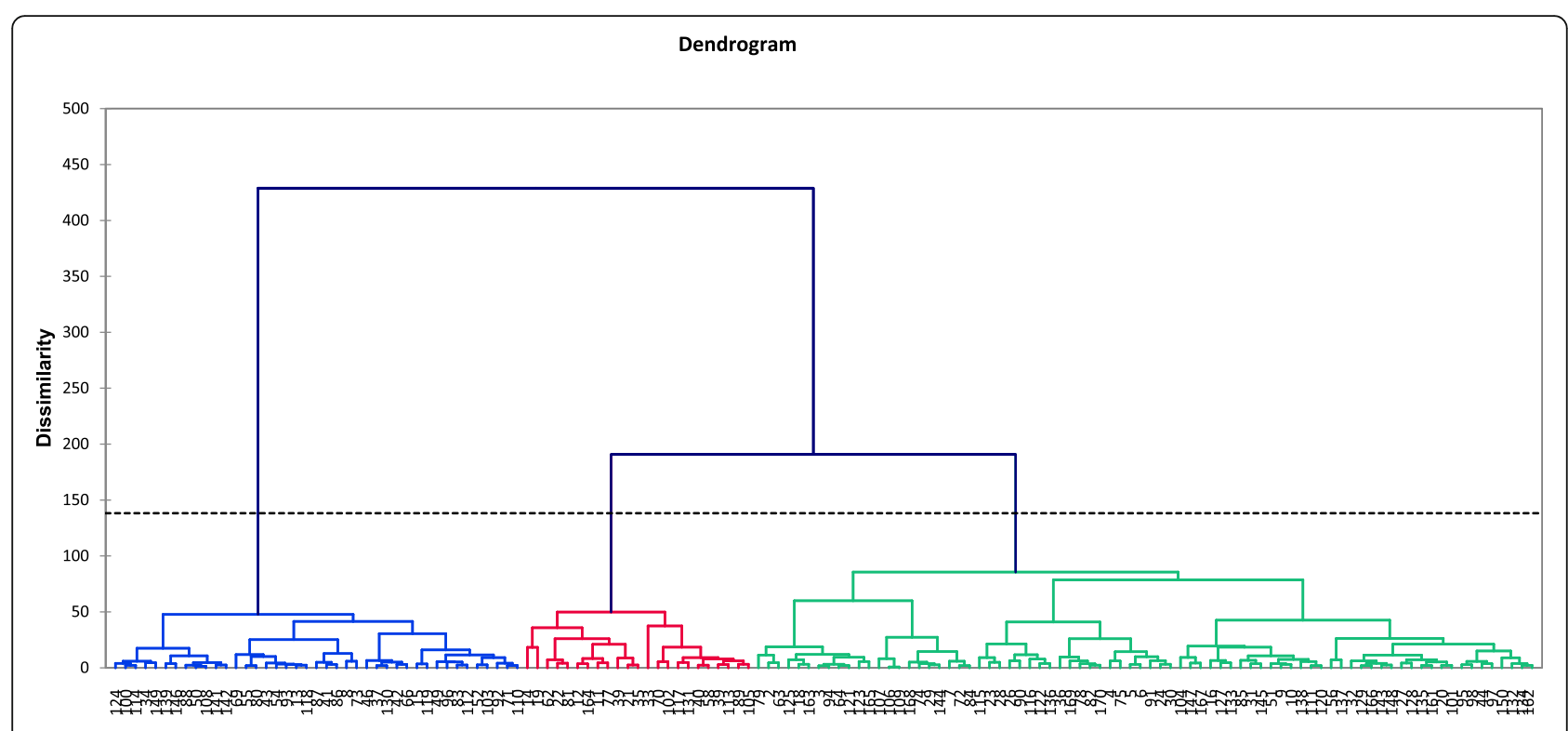

Fig. 2 Cluster analysis-based dendrogram of investigated traits of proso millet genotypes under salinity stress conditions

$5.45 \%$ under normal conditions and 3.33 to $5.21 \%$ under salinity-stress conditions. Furthermore, the values of $\mathrm{R}^{2}$ model ranged from 35.92 to $43.71 \%$ under normal conditions and 36.57 to $43.3 \%$ under salinity-stress conditions. However, the results obtained by GLM model revealed that the $\mathrm{R}^{2}$ varied from $5.22-9.37 \%$ to $5.2-$ 9.97\% under normal and salinity-stress conditions, respectively. Moreover, the values of $\mathrm{R}^{2}$ model varied from 5.81 to $12.3 \%$ under normal conditions and 5.55 to $14.28 \%$ under salinity-stress conditions (data not shown).

According to MLM model, the M14/E10-60, M14/ E10-45, M4/E11-71, M4/E11-70 and M59/E36-1 markers with corresponding variations of 40.58, 40.47,
40.30, 40.15, and 40.09\% demonstrated a significant relationship $(P<0.009)$ with seed yield under normal conditions. Nonetheless, the M14/E10-64, M14/E11-4 and M3/E36-2 markers with corresponding variations of $37.37,36.94$ and $36.57 \%$ revealed such relationship with seed yield under salinity-stress conditions (Additional file 4: Table S4).

Association analysis conducted on proso millet (Panicum miliaceum L.) accessions revealed that M14/E1045, M14/E10-60, M4/E11-44, M4/E11-71, M59/E1170 and M59/E11-75 markers with corresponding variations of $40.83,40.52,40.31,40.18,40.14$, and $40.13 \%$ demonstrated a significant relationship $(P<0.008)$ with forage yield under normal conditions. However, the

Table 9 Statistical variance of 11 AFLP primer combinations for the 143 proso millet genotypes

\begin{tabular}{|c|c|c|c|c|c|c|}
\hline Primer combination & Total Bands & Polymorphic bands & Polymorphic percentage & PIC & Marker Index & Shannon index \\
\hline M3/E10 & 79 & 18 & 22.78 & 0.13 & 2.34 & 0.29 \\
\hline M3/E11 & 51 & 12 & 23.52 & 0.25 & 3 & 0.43 \\
\hline M4/E10 & 81 & 22 & 27.16 & 0.16 & 3.52 & 0.35 \\
\hline M59/E10 & 83 & 37 & 44.57 & 0.48 & 17.76 & 0.90 \\
\hline M59/E36 & 83 & 67 & 80.72 & 0.97 & 64.99 & 1.78 \\
\hline M59/E11 & 82 & 61 & 74.39 & 0.65 & 39.65 & 1.28 \\
\hline M4/E11 & 83 & 74 & 89.15 & 1.06 & 78.44 & 1.93 \\
\hline M14/E11 & 82 & 43 & 52.43 & 0.65 & 27.95 & 1.18 \\
\hline M14/E10 & 83 & 81 & 97.59 & 1.21 & 98.01 & 2.20 \\
\hline M3/E36 & 81 & 50 & 61.72 & 0.57 & 28.50 & 1.13 \\
\hline M4/E36 & 78 & 49 & 62.82 & 0.47 & 23.03 & 0.96 \\
\hline Total & 866 & 514 & 637 & 6.65 & 387.19 & 12.48 \\
\hline Mean & 78.73 & 46.73 & 58 & 0.60 & 35.41 & 1.13 \\
\hline
\end{tabular}



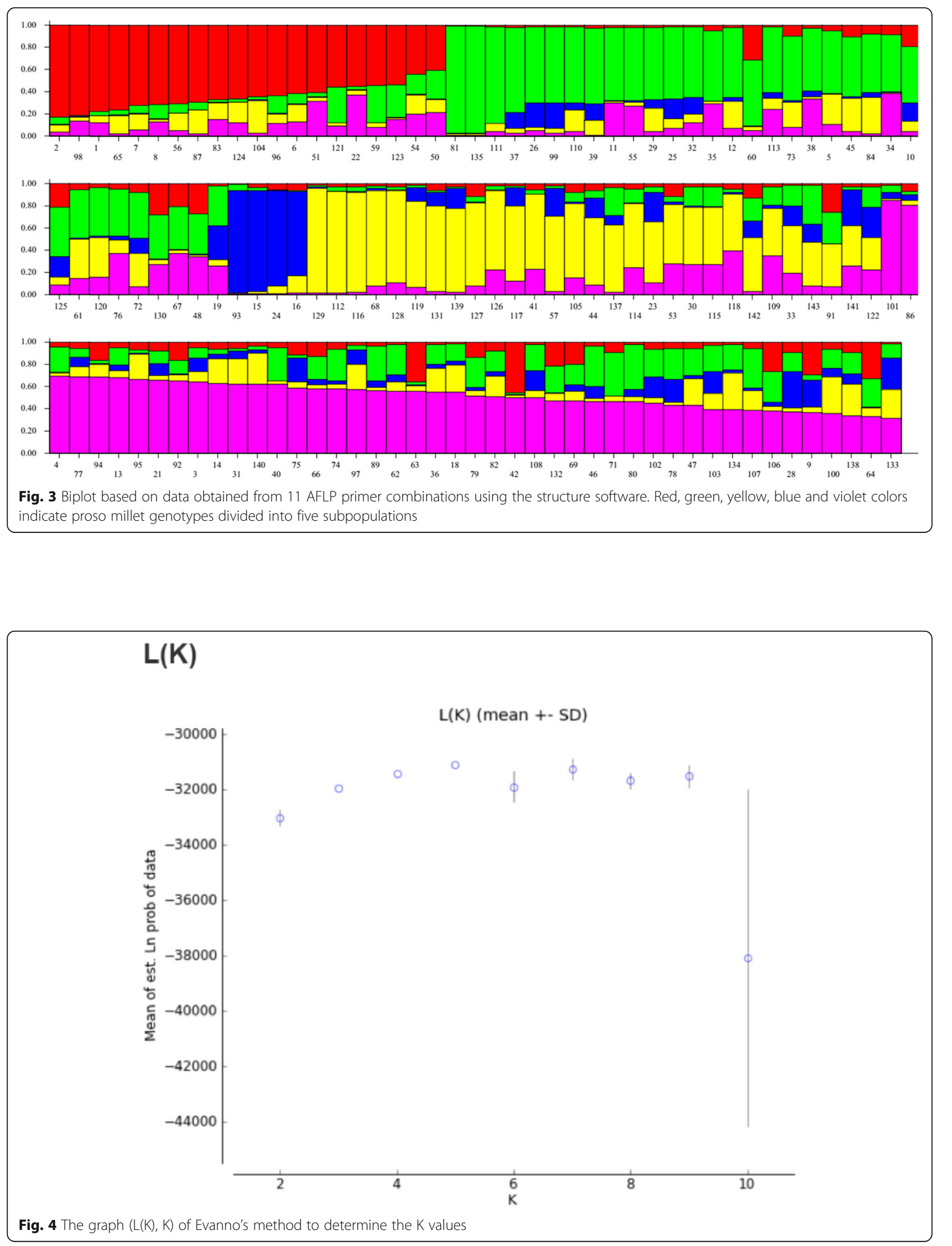


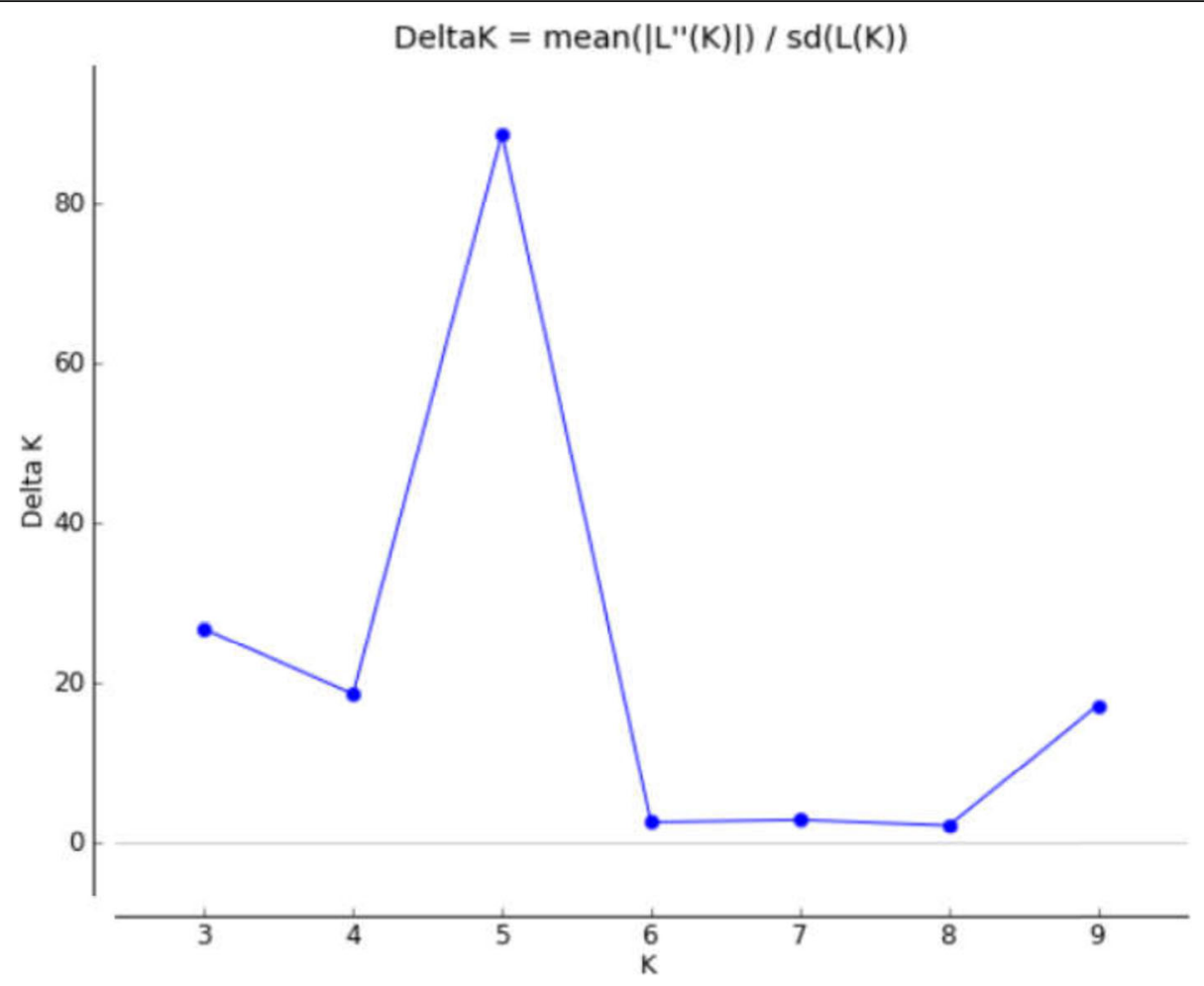

Fig. 5 The graph (Delta K, K) of Evanno's method to determine the $K$ values

M14/E10-64, M3/E36-32 and M14/E10-78 markers with corresponding variations of $38.17 \%, 38.03$ and $37.60 \%$ demonstrated a significant relationship $(P<$ $0.008)$ with forage yield under salinity-stress conditions (Additional file 4: Table S4).

Five markers (M3/E10-3, M59/E36-3, M59/E11-47, M14/E10-69 and M14/E10-40) with corresponding variations of $40.99,40.10,40.03,39.74$ and $30.73 \%$ had strong relationship with the number of leaves per plant under normal conditions while seven markers (M4/E108, M59/E36-3, M59/E36-71, M3/E10-3, M59/E36-74,

Table 10 The results of Evanno's method to determine the $\mathrm{K}$ values

\begin{tabular}{lllllll}
\hline $\mathbf{K}$ & Reps & Mean $\operatorname{LnP}(\mathrm{K})$ & $\mathbf{S t d e v} \operatorname{LnP}(\mathrm{K})$ & $\mathbf{L n}^{\prime}(\mathrm{K})$ & $\mathbf{L n}^{\prime \prime}(\mathrm{K})$ & $\boldsymbol{\Delta K}$ \\
\hline 2 & 5 & $-32,995.26$ & 279.05 & - & - & - \\
3 & 5 & -3194.04 & 19.20 & 1048.22 & 513.46 & 26.73 \\
4 & 5 & $-31,412.28$ & 11.47 & 534.76 & 213.60 & 18.60 \\
5 & 5 & $-31,091.12$ & 12.64 & 32.16 & 1119.96 & 88.58 \\
6 & 5 & $-31,889.92$ & 548.95 & -798.80 & 1425.94 & 2.59 \\
7 & 5 & $-31,262.78$ & 358.87 & 627.14 & 1039.64 & 2.89 \\
8 & 5 & $-31,675.28$ & 262.19 & -412.50 & 574.46 & 2.19 \\
9 & 5 & $-31,513.32$ & 392.33 & 161.96 & 6710.34 & 17.10 \\
10 & 5 & $-38,061.70$ & 608.50 & 6548.38 & - & - \\
\hline
\end{tabular}

The yellow colored row represents $\mathrm{K}$ at maximum values of $\Delta \mathrm{K}$
M14/E10-27 and M14/E10-40) with respective variations of $41.46,41.31,41.30,41.25,41.01,40.92$ and $40.66 \%$ had similar relationship with the number of leaves per plant under salinity-stress conditions (Additional file 4: Table S4).

Moreover, four markers (M4/E11-44, M59/E36-60, M4/E36-4 and M59/E36-76) with corresponding variations of $41.06,40.55,40.46$ and $40.18 \%$ revealed a considerable association $(P<0.006)$ with plant height under normal conditions. However, three markers (M59/E10 23, M59/E11-45 and M59/E36-14) with respective variations of $38.78,38.75 \%$ and 38.15 revealed such an association under salinity-stress conditions, respectively (Additional file 4: Table S4).

The results also indicated that the M4/E36-67, M14/ E10-67, M4/E11-78, M14/E10-44 and M59/E10-64 markers with corresponding variations of $39.20,39.16$, $38.85,38.67$, and $38.24 \%$ demonstrated a significant

Table 11 Molecular variance (AMOVA) of association analysis of AFLP markers in proso millet genotypes by using the structure software

\begin{tabular}{llllll}
\hline Source of variation & Df & MS & Est. Var & $\%$ & PhiPT \\
\hline Among populations & 4 & 153.08 & 3.76 & $7 \%$ & $0.067^{* *}$ \\
Within populations & 138 & 53.90 & 53.90 & $93 \%$ & \\
Total & 142 & & 57.67 & $100 \%$ & \\
\hline
\end{tabular}

**: Significant at 0.01 levels 
relationship $(P<0.009)$ with seed germination percentage under normal conditions. The M3/E10-2, M4/E111, M4/E36-2, M14/E11-44, M4/E36-45 and M4/E1079 markers with corresponding variations of 41.16, $40.84,40.65,39.99,39.98 \%$ and $39.80 \%$ demonstrated a significant relationship with seed germination under salinity-stress conditions (Additional file 4: Table S4).

Furthermore, the M59/E36-39 marker was found to have association with flag leaf length under normal conditions while three markers including M59/E11-20, M59/E11-55, M59/E10-44, M59/E10-24 and M4/E1111 had association with flag leaf length under salinitystress conditions (Additional file 4: Table S4).

The M4/E11-44, M59/E36-37, M3/E36-17, M4/E1140, M3/E11-13 and M4/E11-61 markers with respective variations of $37.39,36.73,36.10,36.04,35.92$ and $35.92 \%$ demonstrated significant association $(P<0.009)$ with the number of panicle branches under normal conditions. Nonetheless, the M4/E36-45, M3/E10-71, M4/E11-76, M4/E11-83, M59/E11-45 and M3/E36-41 with corresponding variations of $38.71,38.36,38.31,37.83,37.47$ and $37.41 \%$ were found to have similar association under salinity-stress conditions (Additional file 4: Table S4).

Furthermore, two markers including M59/E10-83 and M59/E11-82 with respective variations of 42.73 and $42.49 \%$ revealed significant relationship with flag leaf width under normal conditions while three markers including M4/E11-15, M4/E11-25 and M14/ E10-2 with corresponding variations of $42.80,41.83$ and $41.43 \%$ indicated a considerable association with the same trait under salinity-stress conditions (Additional file 4: Table S4).

According to the results, the M59/E10-83, M14/ E10-31 and M59/E36-48 markers with corresponding variations of $42.95,41.55$ and $41.07 \%$ demonstrated a significant relationship with the number of tillers under normal conditions. In contrast, three markers including M4/E11-25, M4/E11-15 and M59/E36-48 with respective variations of 41.57, 41.28 and $40.97 \%$ showed significant relationship with the number of tillers under salinity-stress conditions (Additional file 4: Table S4).

The M4/E10-25, M59/E11-15, M4/E10-48 and M59/ E36-81 markers with respective variations of 40.60 , $40.30,40,39.65$ and $40.87 \%$ demonstrated strong association with panicle length under normal conditions. However, the M4/E10-8, M4/E10-11, M59/E11-18 and M59/E36-31 markers with corresponding variations of $40.37,39.83,39.73,39.51$ and $40.46 \%$ had significant relationship with this trait under salinity-stress conditions (Additional file 4: Table S4).

The results also indicated that the M4/E36-67, M4/ E11-45, M59/E11-9 and M14/E10-19 markers with respective variations of $40.87,40,39.86$ and $39.51 \%$ had a significant relationship $(P<0.008)$ with the number of plants on the line under normal conditions. However, four markers including M14/E11-67, M3/E36-41, M4/E11-31 and M59/E11-39 with corresponding variations of 40.46, 39.86, 39.01 and $38.96 \%$ were found to have similar association with the number of plants on the line under salinity-stress conditions (Additional file 4: Table S4).

It is noteworthy that the M59/E10-22, M59/E11-31, M4/E11-71, M3/E36-45 and M4/E11-61 markers with respective variations of $39.91,39.51,39.33,39.32$ and $38.82 \%$ had a significant relationship with the main panicle seed weight under normal conditions. Six markers including M59/E10-22, M3/E36-45, M4/E11-71, and M59/E11-31, M4/E11-61 and M4/E11-72 with corresponding variations of $39.36,38.85,38.75,38.68,38.62$ and $38.46 \%$ had similar relationship with the main panicle seed weight under salinity-stress conditions (Additional file 4: Table S4).

The association analysis further indicated that the M3/ E36-45, M14/E11-27, M14/E11-44 and M14/E10-69 markers with corresponding variations of $38.78,38.30$, 38.08 and $37.63 \%$ were associated with 1000 -seed weight under normal conditions while five markers including M3/E36-41, M14/E11-44, M14/E11-27, M59/E11-54 and M14/E10-69 with respective variations of 39.64, 39.04, 38.50, 38.46 and 38\% had similar relationship with 1000-seed weight under salinity-stress conditions (Additional file 4: Table S4).

Besides, the M4/E11-44, M4/E11-79, M3/E10-31, M4/E36-31, M14/E10-3, M3/E10-2 and M14/E11-23 markers with corresponding variations of $43.71,43.28$, $43,42.98,42.79,42.51$ and $42.44 \%$ were found to have strong association with the harvest index under normal conditions. Five markers including M14/E11-23, M3/ E36-41, M4/E36-44, M4/E10-8 and M3/E11-13 with respective variations of 43.30, 43.01, 42.91, 42.87 and $42.73 \%$ revealed a strong association with the harvest index $(P<0.004)$ under salinity-stress conditions (Additional file 4: Table S4).

According to the results, under normal conditions, the M14/E10-45, M14/E10-60, M4/E11-44, M4/E11-71, M59/E11-70 and M59/E11-75 markers with corresponding variations of $40.88,40.56,40.32,40.24,40.18$, and $40.15 \%$ demonstrated a significant relationship with the biological yield while two markers including M14/ E10-64 and M3/E36-2 with respective variations of 37.72 and $37.24 \%$ showed similar association with the investigated trait (Additional file 4: Table S4).

To define stable relationships, association analysis was individually performed for each place using MLM model. The results showed that M14/E10-45 and M14/ E10-60 markers (for seed yield), M14/E10-45 and M4/ E11-44 markers (for forage yield), M14/E11-27 marker 
(for 1000-seed weight), M59/E36-37 marker (for the number of panicle branches), M59/E36-39 marker (for flag leaf length), M59/E10-22 marker (for main panicle seed weight) and M59/E10-83 marker (for the number of tillers) had a significant and stable association in all environments under normal conditions.

On the other hand, the M4/E11-45 marker (for seed germination percentage), M14/E10-14, M14/E10-64 markers (for seed yield), M14/E11-44 marker (for 1000seed weight), M14/E10-64 marker (for forage yield), M59/E36-37 marker (for the number of panicle branches), M3/E36-45 marker (for main panicle seed weight) and M59/E36-48 marker (for the number of tillers) had significant and stable association in all environments under salinity-stress conditions.

\section{Discussion}

The association analysis method has advantages over the Quantitative Trait Locus (QTL) method. The main advantages include bi-parental population performance, clear increment mapping and decreased investigation period as well as taking into account more alleles [41]. This method is sometimes used for proso millet (Panicum miliaceum L.) especially in dealing with different environmental conditions such as the salinity stress. It is employed to locate salinity-derived genes and use of various traits. The optimum application of this information would lead to improvements in the efficiency of MAS projects. In this context, developing knowledge could help protect the germplasm resources and the diversity of inherited traits. Moreover, it facilitates the determination of appropriate plants by markers with the purpose of breeding programs and other genetic researches [42].

According to the analysis of phenotypic data, genotypes varied considerably around the measured traits. This also indicates a significant genetic variation among the investigated genotypes. Based on the results, all traits were highly influenced by the environment and the genotype $\times$ environment interaction under both normal and salinity-stress conditions. Mehrani et al. [43] studied 10 proso millet genotypes in three locations to evaluate the correlations between seed yield and major agronomic traits. They found positive and significant correlations between seed yield and traits such as number of tillers, number of leaves and straw yield. Their observations were in agreement with the results of this research. In another investigation carried out on proso millet genotypes, Sing and Rao found [44] positive and significant correlations between seed yield and major agronomic traits such as straw weight, plant weight, panicle length and the number of tillers. In another research conducted on 14 morphological traits corresponding to 39 foxtail millet cultivars, Reddy and Larshmi [45] observed positive correlations between seed yield and the number of tillers, the number of fertil tillers, the biological yield as well as harvest index. As harvest index and biological yield had the highest effect on the seed yield, it was recommended to use these two specific traits as criteria to select superior cultivars. Since the results of this research are consistent with findings of previous investigations, those traits evaluated in various researches deserve more attention for breeding programs as well as selecting genotypes with the purpose of improving seed and forage yields.

Cluster analysis and disintegration into the principal components are effective tools to distinguish proso millet genotypes. According to this research, by disintegrating into the principal components, the first four main principal components could justify 59.94 and $62.48 \%$ of the whole variance of the investigated traits under normal and salinity-stress conditions, respectively. These results are in agreement with findings of [46]. They declared that the analysis of the principal principal components demonstrated that plant height, seed yield, number of tillers and 1000 seed- weight could be employed to distinguish the superior of proso millet genotypes.

Based on the cluster analysis, all genotypes were categorized into three groups. Compared to other groups, the second group of genotypes had superior seed and forage yields. Besides, the common genotypes held in the second group (G8, G13, G15, G34, G37, G43, G46, G49, G52, G54, G55, G69, G88, G119, G139, G146) had significant superiority in terms of seed and forage yields under both normal and salinity-stress conditions. Therefore, they could be used as superior genotypes of proso millet germplasm in future breeding studies. Similar observations were made in a research conducted on Taiwan-based foxtail millet in which three clusters were determined [47]. In another investigation carried out on foxtail millet, six major clusters were obtained [48]. However, this research led to the identification of three clusters. The difference observed in the number of clusters could be attributed to the different plant species as well as the number of investigated genotypes.

Therefore, it is essential to perform experimental association analysis in different places. The substantial percentage of polymorphism indicated that using AFLP combination in this research could be useful to find proso millet (Panicum miliaceum L.) genotypes. The findings of this study are in agreement with the results of other investigations conducted on millet $[35,49]$.

According to the allele diversity discussed in this investigation, the M14/E10 primer combination had the highest level of polymorphic percentage as well as high PIC, MI and Shannon index. Therefore, this marker can 
be regarded as the best combination for accessions of proso millet (Panicum miliaceum L.).

The structure analysis demonstrated that accessions could be divided into five groups with various genetic structures. Moreover, the results showed that use of AFLP marker might be useful and efficient for population structure analysis which is in agreement with Kumar et al. [26]. According to their study, the AFLP could be used as an indicator for genetic categorization, manufacturing of linkage maps, mapping of agronomic traits and devoting parentage. Moreover, the results of association analysis revealed that the number of considerable markers decreased in the MLM compared to the GLM model. The combination of population structure and kinship in the MLM model would decrease fake affirmative associations. This indicated that the identification of some alleles in the GLM model might be due to the genotypic association with the corresponding traits.

These results are in agreement with the investigations conducted by $\mathrm{Yu}$ et al. [30] and Dadras et al. [50]. Furthermore, according to the results, the determination coefficient obtained by MLM model was significantly reduced compared to the one achieved by GLM model. Thus, AFLP markers used by MLM model might be good candidates for future studies. These results are in agreement with the findings of Achleitner et al. [51].

Although markers must be validated by examining their effectiveness on definitive goal-oriented phenotypes among absolute populations with diverse genetic backgrounds [52], the markers indicating the greatest effect on the traits would be the best candidates in future MAS studies. Association analysis using the MLM model demonstrated that the M14/E10-45 and M14/E10-60 markers had significant relationship with forage and seed yields under normal conditions. Furthermore, the M14/E10-64 marker had a significant and permanent relationship with seed and forage yields in all environments under salinity-stress conditions. If markers have substantial effects on traits, they can be useful in programs such as MAS under salinity-stress conditions. The variation range of phenotypic traits was calculated separately for each marker. The lower values indicate that these complicated traits might be controlled by other genes with smaller effects. Moreover, a low range of $\mathrm{R}^{2}$ value for each trait might be attributed to insufficient density of markers, insignificant quantitative effect of markers, scarce alleles and complicated allelic interactions $[53,54]$.

According to the MLM model, the M14/E10-45 and M14/E10-60 markers simultaneously had significant association with seed and forage as well as biological yields under normal and salinity-stress conditions. Shi et al.
[55] suggested local QTLs for yield and other traits. It is quite natural that yield is defined based on the accumulative effect of different traits. The genes known to be effective show the effects of polytrophic at least on one trait [56]. Furthermore, the association of M4/E11-44 marker with seed germination percentage, seed and forage yields, the association of the M4/E11-61marker with the number of panicle branches and seed weight of main panicle as well as the significant and permanent relationship of the M14/E10-64 marker with seed and forage yields in all environments under salinity-stress conditions could be attributed to pleiotropic effects or the multiple linked genes in that region which influence some of those traits. Therefore, these markers can be highly useful for breeding these traits under salinitystress conditions. Moreover, the M14/E10-27 and M14/ E10-40 markers (for the number of leaves) and the M4/ E10-8 and M59/E11-18 markers (for panicle length) had a significant and stable association in all environments under salinity-stress conditions.

\section{Conclusions}

According to the analysis of phenotypic data, the wide germplasm of Iranian proso millet (143 studied genotypes) varied significantly in terms of measured traits. Moreover, the effects of environment as well as the genotype $x$ environment interaction were significant under both normal and salinity stress conditions. These results indicated the existence of a considerable diversity among the germplasm, facilitating the selection and classification of genotypes especially salinity stress- resistance ones. Therefore, the investigation of association analysis of these germplasms in different environmental conditions will be important.

The results of the association analysis conducted on the investigated traits of proso millet demonstrated that most of the markers which control the traits had an acceptable level of polymorphism and diversity under normal and salinity-stress conditions. Furthermore, the primer combinations used in this study showed a high percentage of polymorphism and a high level of reliability in terms of PIC, MI and Shannon indices. Therefore, the marker compounds employed in this study can be considered a powerful tool to distinguish proso millet genotypes.

According to the results obtained by MLM model, a number of markers showed a considerable association and stability under both normal and salinity- stress conditions. Moreover, a number of markers had a significant relationship with several traits in all environments which might be due to the pleiotropic effects or strong association of several genes which affect a number of traits. Therefore, the introduced markers of this study showing significant relations with traits under salinity stress 
conditions could be suitable candidates to be used in future MAS studies to improve salinity-resistance genotypes of Panicum miliaceum in arid and semiarid areas.

\section{Methods}

\section{Plant materials}

This research is a part of Iran's comprehensive research program running at the Iranian center of excellence for drought-resistance crops at the University of Kerman. The 143 proso millet (Panicum miliaceum L.) genotypes (Additional file 5: Table S5) were supplied by the Iranian center of excellence for drought-resistance crops at the University of Kerman. All studied genotypes collected by the center of excellence were selected from various regions of Iran with a long history of millet cultivation. For sampling, all necessary measures were taken according to the recommendations provided by Gene Bank Guidelines. All genotypes were locally-cultivated and no wild types were used in this research. The salinity-stress related traits of Iranian proso millet are wider than those of international millet genotypes. The field used for the experiments is located in the Iranian center of excellence for drought and salinity-resistance crops at longitude $56^{\circ} 54^{\prime} \mathrm{E}$ and latitude $30^{\circ} 20^{\prime} \mathrm{N}$. It is situated $1755 \mathrm{~m}$ above the sea level. The soil is clayey loam.

\section{Planting and performing salt stress treatment}

The varieties were cultivated in two locations at the research institute of salinity stress (Shahid-Bahonar University of Kerman and Ekhtiyarabad fields) under two conditions (normal and saline) over a 2 year- long period (2017 and 2018). Experimental design was performed in randomized complete block with 3 replications. Irrigation treatment was conducted under (i) non-stress and (ii) salinity- stress conditions from the beginning of plant growth to the end of seed filling. The field preparation operations such as plowing, weeding, fragmentation, fertilization and irrigation were regularly conducted at appropriate time intervals over the whole period of the experiments. The soil $\mathrm{pH}$ was determined 7.41 and 8.1 in Kerman and Ekhtiarabad fields, respectively. Furthermore, the electrical conductivity of irrigation waters used in Kerman and Ekhtiarabad fields were estimated 2.5 and $8.7 \mathrm{dS} / \mathrm{m}$, respectively.

\section{Genomic DNA extraction}

The genomic DNA was extracted from pristine leaves based on the Cetyltrimethyl ammonium bromide (CTAB) Doyle and Doyle [57] method. DNA quantity control was performed using DNA spectrophotometer spectrum and agarose electrophoresis. Moreover, amplified fragment length polymorphism was conducted according to Vos et al. [58]. The amplification process was carried out by applying 11 superlative instructive EcoRI/ MseI primer combinations (Table 12). Initially, five hundred ng of each DNA sample was digested with ten units of MseI (5 U) and EcoRI (5 U) enzymes. Then, these samples were treated with EcoRI and then incubated at $37^{\circ} \mathrm{C}$ and $65^{\circ} \mathrm{C}$, each for $16 \mathrm{~h}$, respectively. Besides, they were exposed to EcoRI and MseI enzymes in a thermocycler at $65^{\circ} \mathrm{C}$ for $16 \mathrm{~h}$. Ligated DNA was diluted with water at 1:8 ratios and the pre-amplification process was conducted using primers and selective nucleotides. The reaction was completed in a $25 \mu \mathrm{l}$ volume. The products of the pre-amplification stage were treated with primers as well as three selective nucleotides. The final propagation stage was conducted by 13 cycles of $30 \mathrm{~s}$ at $94 \mathrm{C}, 30$ $\mathrm{s}$ at $65 \mathrm{C}$ as touchdown with $0.7 \mathrm{C}$ lowering for each cycle, and $1 \mathrm{~min}$ at $72 \mathrm{C}$. The PCR continued by another 20 cycles of $30 \mathrm{~s}$ at $94 \mathrm{C}, 30 \mathrm{~s}$ at $56 \mathrm{C}$ and $1 \mathrm{~min}$ at $72 \mathrm{C}$, and one final cycle of extension at $72 \mathrm{C}$ for $10 \mathrm{~min}$. In order to analyze the results of the PCR selective stage based on the 0 M700 method, the QIAxcel device and kit's High Resolution (QIAGEN, Hilden, Germany) were employed. The QX adjustment marker (15 bp/1 kp) was applied in this process.

Table 12 Primer combinations used in the analysis of amplified fragment length polymorphism (AFLP) of proso millet genotypes

\begin{tabular}{llr}
\hline Code of primer combination & Code Sequence for Msel & Code Sequence for EcoRI \\
\hline M14/E11 & Msel Selective Primer+CTG & EcoRI Selective primer+AGC \\
M59/E36 & Msel Selective Primer+CTA & EcoRI Selective primer+AGC \\
M4/E10 & Msel Selective Primer+CTT & EcoRI Selective primer+AGC \\
M3/E11 & Msel Selective Primer+CAA & EcoRI Selective primer+AGC \\
M4/E11 & Msel Selective Primer+CTT & EcoRI Selective primer+AGC \\
M59/E11 & Msel Selective Primer+CTA & EcoRI Selective primer+AGC \\
M59/E10 & Msel Selective Primer+CTA & EcoRI Selective primer+AGC \\
M4/E36 & Msel Selective Primer+CTT & EcoRI Selective primer+AGC \\
M3/E36 & Msel Selective Primer+CAA & EcoRI Selective primer+AGC \\
M14/E36 & Msel Selective Primer+CTT & EcoRI Selective primer+AGC \\
M3/E10 & Msel Selective Primer+CAA & EcoRI Selective primer+AGC \\
\hline
\end{tabular}




\section{Phenotyping evaluation}

The traits evaluated in this investigation included seed germination (\%), plant height $(\mathrm{cm})$, the number of leaves per plant, flag leaf length $(\mathrm{cm})$, flag leaf width $(\mathrm{cm})$, the number of tillers, panicle length $(\mathrm{cm})$, main panicle seed weight $\left(\mathrm{g} / \mathrm{m}^{2}\right)$, the number of panicle branches, the number of plants on the line, 1000-seed weight, harvest index, forage yield ( $t / h a)$, biological yield ( $t / h a)$ and seed yield $(\mathrm{t} / \mathrm{ha})$. The last three traits including forage yield, biological yield and seed yield were initially measured based on $\mathrm{g} / \mathrm{m}^{2}$ and then converted to ton per hectare $(\mathrm{t} /$ ha) (Table 13).

\section{Statistical analyses}

\section{Phenotypic data analysis}

Analysis of variance (ANOVA) was conducted based on complete block design (RCBD). Since the data obtained via a randomized complete block (RCBD) design are comparable to the lattice (data not presented), the observed data were standardized for each trait and ANOVA was carried out deep-seated on RCBD by SAS software v. 9.1 [59]. Broad-sense heritability of essential agronomic traits related to salt tolerance for each experiment was estimated according to Nyquist [60]:

$$
H^{2}=\sigma_{g}^{2} /\left(\sigma_{g}^{2}+\sigma_{g e}^{2} / e+\sigma_{\varepsilon}^{2} / r e\right)
$$

Where $\sigma_{g}^{2}, \sigma_{g e}^{2}$ and $\sigma_{\varepsilon}^{2}$ denote the genetic variance, genetic $\times$ environment interactive variance and the remaining error variance, respectively. Moreover, $e$ and $r$ are the number of environments and replicates per environment, respectively.

Table 13 Names and code of investigated traits in the 143 proso millet genotypes.

\begin{tabular}{lll}
\hline Trait & Code of traits & Unit \\
\hline Seed germination & 1 & $\%$ \\
Plant height & 2 & $\mathrm{~cm}$ \\
Number of leaves per plant & 3 & - \\
Flag leaf length & 4 & $\mathrm{~cm}$ \\
Flag leaf width & 5 & $\mathrm{~cm}$ \\
Number of tillers & 6 & - \\
Panicle length & 7 & $\mathrm{~cm}$ \\
Main panicle seed weight & 8 & $\mathrm{~g} / \mathrm{m}^{2}$ \\
Number of panicle branches & 9 & - \\
Number of plants on the line & 10 & - \\
Seed yield & 11 & $\mathrm{t} / \mathrm{ha}$ \\
1000-seed weight & 12 & $\mathrm{~g} / \mathrm{m}^{2}$ \\
Forage yield & 13 & $\mathrm{t} / \mathrm{ha}$ \\
Harvest index, forage yield & 14 & $\%$ \\
Biological yield & 15 & $\mathrm{t} / \mathrm{ha}$ \\
\hline
\end{tabular}

\section{Correlation coefficients analysis}

The phenotypic correlation coefficients are used to evaluate the relationships among yield and its members as well as those among members of a specific yield. In this section, the pair-wise phenotypic correlation for all traits were calculated using SAS software v.9.1. Then, their significance was tested.

\section{Principal component analysis}

Regarding diversity among the investigated genotypes, principal component analysis was used to determine the effect of each trait as well as the overall classification of genotypes. Besides, in order to better understand the genotypes' behavior and having a more effective selection and determining the effectiveness of each trait under normal and salinity-stress conditions, this process was conducted separately using SAS software v.9.1.

\section{Cluster analysis}

For grouping the lines, cluster analysis was conducted by Ward's method based on Cofenticcoefficient. Moreover, the squared Euclidean distance was employed as similarity index. The SAS software v.9.1 was used in this analysis.

\section{Molecular data analysis}

For each primer combination, expositive statistical analysis was initially performed using GenAlEx software v. 6.5b3 for each primer combination [61]. The marker index (MI) which indicates marker's efficiency, [62], Shannon's index $(H)$, [63], and polymorphic information content (PIC) [64] were evaluated. However, the Shannon's index $(\mathrm{H})$ is among the most popular techniques used to evaluate the genetic diversity. These indicators were determined based on the following relations:

$$
\begin{aligned}
& P I C=1-p^{2}-q^{2} \\
& M I=P I C \times \text { number of polymorphic loci } \\
& H=-1 \times(p \times \ln (p)+q \times \ln (q))
\end{aligned}
$$

The symbols $p$ and $q$ are the frequency of prevailing and unvalued alleles, respectively.

Analysis of molecular variance (AMOVA), as a method to calculate F-statistics among and within subpopulations, was performed by GenAlEx software v. 6.5b3 [31, 65]. The PhiPT statistics (analogy of FST, fixation index) was employed to measure the genetic difference among subpopulations:

$$
P h i P T=A P / W P+A P
$$

The symbols $A P$ and WP denote the approximate variance among and within populations, respectively. 


\section{Population structure}

Population structure was determined using STRUCT URE software v. 2.3.4 and performed with 10 replicates for each simulation from $\mathrm{K}=2$ to 10 followed by 100 , 000 Markov chain Monte Carlo (MCMC) iterations. Furthermore, the blend model and correlated allele frequencies were selected for this analysis. The optimum $K$ was determined based on $\Delta \mathrm{K}$ calculated by the following equation:

$$
\Delta K=m\left|L^{\prime \prime}(K)\right| / \mathrm{s}[\mathrm{L}(\mathrm{K})]
$$

The web page of STRUCTURE HARVESTER processing uses an optimum estimate of $K$ value representing the maximum value of $\Delta K[40,66]$.

\section{Association analysis}

TASSEL software v. 4.2.1 [32] was employed to find considerable associations among the population-level allele frequencies and morphological traits. The association analysis was performed using both GLM and MLM models [30]. To this end, the GLM model and the most stringent MLM model were applied. The $P$ matrix estimated in both normal and salinity-stress experiment was used for significant associations. Moreover, the $Q$ matrix was calculated based on the structural analysis (at highest $\Delta K$ ) and used as a variable to modify the population structure in both models. Also, TASSEL software v. 4.2.1 was used to find the kinship matrix (K-matrix) based on the effects of markers as well as the phenotype of traits [32].

\section{Supplementary information}

Supplementary information accompanies this paper at https://doi.org/10. 1186/s12870-020-02639-2.

Additional file 1: Table S1. Combined ANOVA of the 143 proso millet genotypes under two conditions (normal and salt stress)) with 3 replications in 2 environments.

Additional file 2: Table S2. Code of genotypes categorized into three main clusters resulting from cluster analysis under normal conditions.

Additional file 3: Table S3. Code of genotypes categorized into three main clusters resulting from cluster analysis under salinity stress conditions.

Additional file 4: Table S4. Association analysis of 143 proso millet genotypes under normal and salt stress conditions based on the MLM model.

Additional file 5: Table S5. Geographical location and code of the collected proso millet (Panicum miliaceum L.) genotypes.

\section{Abbreviations}

AFLP: Amplified fragment length polymorphism; MLM: Mixed linear model; GWAS: Genome-wide association study; GLM: General Linear Model; MAS: Marker-assisted selection; LD: Linkage disequilibrium; RAPD: Random amplified polymorphic DNA; PIC: Polymorphic Information Content index; $\mathrm{H}$ : Shannon index; MI: Marker index; PhiPT: Analogue stabilization index; QTL: Quantitative Trait Locus; CTAB: Cetyltrimethyl ammonium bromide

\section{Acknowledgements}

The authors would like to appreciate the support provided by the Research and Technology Institute of Plant Production (RTIPP) and Iranian Center of excellence for drought and salinity tolerant crops, Shahid- Bahonar University of Kerman, Iran and Vice Chancellor for Research and Technology, University of Zabol, Iran.

\section{Authors' contributions}

All authors have contributed to carry out this research. M.Y. performed the experiments and carried out data analyses; L.F. Supervisor and the final manuscript version; G. MN was the project coordinator and program leader for millet research programs; L.F. and G. MN. jointly designed the experiments; M.S. edited and B.N. assisted in preparing the initial manuscript draft. All authors have read and approved the manuscript.

\section{Funding}

Authors appreciate Iranian center of excellence for breeding of drought and salinity tolerant crops and also Research and Technology Institute of Plant Production-Shahid-Bahonar University of Kerman for providing genetic materials and the design of the study and collection, analysis, and interpretation of data. Also this investigation was supported by a research grant (UOZ-GR9517-43) for in writing the manuscript provided by the University of Zabol.

\section{Availability of data and materials}

The dataset generated and analyzed during the study are included in this published article and its supplementary information files, or are available from the corresponding authors on reasonable request.

\section{Ethics approval and consent to participate}

Not applicable.

\section{Consent for publication}

Not applicable.

\section{Competing interests}

The authors declare that they have no competing interests.

\section{Author details}

${ }^{1}$ Department of Plant Breeding and Biotechnology, Faculty of Agriculture, University of Zabol, Zabol, Sistan and Baluchestan province, Iran.

${ }^{2}$ Department of Agronomy and Plant Breeding, College of Agriculture, Shahid Bahonar University of Kerman, Kerman 76169-133, Iran. ${ }^{3}$ Department of Molecular Physiology, Agricultural Biotechnology Research Institute of Iran, Mahdasht Rd, Karaj 31535-1897, Iran.

Received: 3 April 2020 Accepted: 4 September 2020 Published online: 15 September 2020

\section{References}

1. Lu H, Zhang J, Liu KB, Wu N, Li Y, Zhou K, Ye M, Zhang T, Zhang H, Yang X, Shen L. Earliest domestication of common millet (Panicum miliaceum) in East Asia extended to 10,000 years ago. Proc Natl Acad Sci. 2009;106(18): 7367-72.

2. Anderson $\mathrm{E}$, Martin $\mathrm{JH}$. World production and consumption of millet and sorghum. Econ Bot. 1949;3(3):265-88.

3. Grabouski PH. Selective control of weeds in proso millet with herbicides. Weed Sci. 1971;19(3):207-9.

4. Baltensperger DD. Progress with proso, pearl and other millets. Trends new Crop and new uses. In: Proceedings of the fifth national symposium Atlanta, Georgia, USA, 10-13 Nov 2001. Alexandria: ASHS Press; 2002. p. 100-103.

5. Lágler R, Gyulai G, Humphreys M, Szabó Z, Horváth L, Bittsánszky A, Kiss J, Holly L, Heszky L. Morphological and molecular analysis of common millet (P. miliaceum) cultivars compared to an aDNA sample from the 15th century (Hungary). Euphytica. 2005;146(1-2):77-85.

6. Goron TL, Raizada MN. Genetic diversity and genomic resources available for the small millet crops to accelerate a new green revolution. Front Plant Sci. 2015;6:157.

7. Saha D, Gowda MC, Arya L, Verma M, Bansal KC. Genetic and genomic resources of small millets. Crit Rev Plant Sci. 2016;35(1):56-79.

8. Dong $Y$, Duan S. Production of transgenic millet plants via particle bombardment. Acta Botan Boreali-Occiden Sin. 2000;20(2):175-8. 
9. Dwivedi SL, Upadhyaya HD, Senthilvel S, Hash CT, Fukunaga K, Diao X, Santra D, Baltensperge D, Prasad M. Millets: genetic and genomic resources. In: Plant Breeding Reviews. Hoboken: Wiley-Blackwell; 2012. p. 247-375.

10. Ashraf M. Organic substances responsible for salt tolerance inEruca sativa. Biol Plant. 1994;36(2):255-9

11. Khan MB, Shafi M, Bakht J. Yield and yield components of pearl millet as affected by various salinity levels. Pak J Biol Sci. 2000;3:1393-6.

12. Flowers TJ. Improving crop salt tolerance. J Exp Bot. 2004;55(396):307-19.

13. Munns R, James RA. Screening methods for salinity tolerance: a case study with tetraploid wheat. Plant Soil. 2003;253(1):201-18

14. Ahmed T, Scholz M, Al-Faraj F, Niaz W. Water-related impacts of climate change on agriculture and subsequently on public health: a review for generalists with particular reference to Pakistan. Int J Environ Res Public Health. 2016;13(11):1051

15. Munns R, Tester M. Mechanisms of salinity tolerance. Annu Rev Plant Biol. 2008;59:651-81

16. Melchinger AE. Use of RFLP markers for analysis of genetic relationships among breeding materials and prediction of hybrid performance. Int Crop Science I. 1993;1:621-8.

17. Johns MA, Skroch PW, Nienhuis J, Hinrichsen P, Bascur G, Muñoz-Schick C. Gene pool classification of common bean landraces from Chile based on RAPD and morphological data. Crop Sci. 1997;37(2):605-13.

18. Thompson JA, Nelson RL. Core set of primers to evaluate genetic diversity in soybean. Crop Sci. 1998;38(5):1356-62.

19. Brown-Guedira GL, Thompson JA, Nelson RL, Warburton ML. Evaluation of genetic diversity of soybean introductions and north American ancestors using RAPD and SSR markers. Crop Sci. 2000;40(3):815-23.

20. Hair JF. ua (1995): Multivariate data analysis with readings. Englewood Cliffs: Prentice Hall; 1995.

21. Huber PJ, Ronchetti E. Robust statistics Wiley. New York. 1981; 1(1).

22. Hallauer AR, Russell WA, Lamkey KR. Corn breeding. Corn and corn improvement, vol. 18; 1988. p. 463-564.

23. Morton MJ, Awlia M, Al-Tamimi N, Saade S, Pailles Y, Negrão S, Tester M. Salt stress under the scalpel-dissecting the genetics of salt tolerance. Plant J. 2019;97(1):148-63.

24. Marić S, Bolarić S, Martinčić J, Pejić I, Kozumplik V. Genetic diversity of hexaploid wheat cultivars estimated by RAPD markers, morphological traits and coefficients of parentage. Plant Breed. 2004:123(4):366-9.

25. Paun O, Schönswetter P. Amplified fragment length polymorphism: an invaluable fingerprinting technique for genomic, transcriptomic, and epigenetic studies. Methods Mol Biol. 2012;862:75-87. https://doi.org/10. 1007/978-1-61779-609-8 7

26. Kumar S, Ambreen H, Murali TV, Bali S, Agarwal M, Kumar A, Goel S, Jagannath A. Assessment of genetic diversity and population structure in a global reference collection of 531 accessions of Carthamus tinctorius L.(safflower) using AFLP markers. Plant Mol Biol Report. 2015; 33(5):1299-313.

27. Mackay I, Powell W. Methods for linkage disequilibrium mapping in crops. Trends Plant Sci. 2007:12(2):57-63.

28. Zhu C, Gore M, Buckler ES, Yu J. Status and prospects of association mapping in plants. Plant Genome. 2008;1 (1):5-20.

29. Parisseaux $B$, Bernardo R. In silico mapping of quantitative trait loci in maize. Theor Appl Genet. 2004;109(3):508-14.

30. Yu J, Pressoir G, Briggs WH, Bi IV, Yamasaki M, Doebley JF, McMullen MD, Gaut BS, Nielsen DM, Holland JB, Kresovich S. A unified mixed-model method for association mapping that accounts for multiple levels of relatedness. Nat Genet. 2006;38(2):203.

31. Pritchard JK, Stephens M, Rosenberg NA, Donnelly P. Association mapping in structured populations. Am J Hum Genet. 2000;67(1):170-81.

32. Bradbury PJ, Zhang Z, Kroon DE, Casstevens TM, Ramdoss Y, Buckler ES. TASSEL: software for association mapping of complex traits in diverse samples. Bioinformatics. 2007;23(19):2633-5.

33. Karam D, Westra P, Nissen SJ, Ward SM, Figueiredo JE. Genetic diversity among proso millet (Panicum miliaceum) biotypes assessed by AFLP technique. Planta Daninha. 2004;22(2):167-74.

34. Karam D, Westra P, Niessen SJ, Ward SM, Figueiredo JE. Assessment of silver-stained AFLP markers for studying DNA polymorphism in proso millet (Panicum miliaceum L.). Braz J Botany. 2006;29(4):609-15.

35. Le Thierry d'Ennequin M, Panau O, Toupance B. Assessment of genetic relationships between Setaria italica and its wild relative $S$. viridis using AFLP markers. Theor Appl Genet. 2000;100:1061-6.
36. Colosi JC, Schaal BA. Wild proso millet (Panicum miliaceum) is genetically variable and distinct from crop varieties of proso millet. Weed Sci. 1997: 45(4):509-18.

37. Rajput SG, Plyler-Harveson T, Santra DK. Development and characterization of SSR markers in proso millet based on switchgrass genomics. Am J Plant Sci. 2014;5(01):175.

38. Ebrahimi F, Majidi MM, Arzani A, Mohammadi-Nejad G. Association analysis of molecular markers with traits under drought stress in safflower. Crop Pasture Sci. 2017:68(2):167-75.

39. Mohlke KL, Lange EM, Valle TT, Ghosh S, Magnuson VL, Silander K, Watanabe RM, Chines PS, Bergman RN, Tuomilehto J, Collins FS. Linkage disequilibrium between microsatellite markers extends beyond $1 \mathrm{CM}$ on chromosome 20 in Finns. Genome Res. 2001:11(7):1221-6.

40. Evanno G, Regnaut S, Goudet J. Detecting the number of clusters of individuals using the software STRUCTURE: a simulation study. Mol Ecol. 2005;14(8):2611-20.

41. Reich DE, Cargill M, Bolk S, Ireland J, Sabeti PC, Richter DJ, Lavery T, Kouyoumjian R, Farhadian SF, Ward R, Lander ES. Linkage disequilibrium in the human genome. Nature. 2001:411(6834):199.

42. Mwadzingeni L, Shimelis H, Rees DJ, Tsilo TJ. Genome-wide association analysis of agronomic traits in wheat under drought-stressed and nonstressed conditions. PLoS One. 2017;12(2):e0171692.

43. Mehrani A, Mosavat A, Shushi A. The study of final yield comparison of hopeful cultivars of foxtail millet. Division Corn Feed. 2007;9(3):592-282.

44. Singh KD, Nagaraja RM. Association analysis in foxtail millet [Setaria italica (L. ) Beauv]. J Res APAU. 1989:68-9.

45. Reddy CD, Jhansilakshmi K. Variability and Path Analysis of Component Characters in Foxtall Millet. J Maharashtra Agric Univ. 1991;16:44.

46. Salini K, Nirmalakumari A, Muthiah AR, Senthil N. Evaluation of proso millet (Panicum miliaceum L.) germplasm collections. Electronic J Plant Breed. 2010;1 (4):489-99.

47. Lin HS. Genetic diversity in the foxtail millet (Setaria italica) germplasm as determined by agronomic traits and microsatellite markers. Aust J Crop Sci. 2012;6(2):342-9.

48. Liu Z, Bai G, Zhang D, Zhu C, Xia X, Cheng R, Shi Z. Genetic diversity and population structure of elite foxtail millet [Setaria italica (L.) P. Beauv.] germplasm in China. Crop Sci. 2011;51(4):1655-63.

49. Gupta S, Kumari K, Das J, Lata C, Puranik S, Prasad M. Development and utilization of novel intron length polymorphic markers in foxtail millet (Setaria italica (L.) P. Beauv.). Genome. 2011;54(7):586-602.

50. Dadras AR, Sabouri H, Nejad GM, Sabouri A, Shoai-Deylami M. Association analysis, genetic diversity and structure analysis of tobacco based on AFLP markers. Mol Biol Rep. 2014:41(5):3317-29.

51. Achleitner A, Tinker NA, Zechner E, Buerstmayr H. Genetic diversity among oat varieties of worldwide origin and associations of AFLP markers with quantitative traits. Theor Appl Genet. 2008;117(7):1041-53.

52. Collard BC, Jahufer MZ, Brouwer JB, Pang EC. An introduction to markers, quantitative trait loci (QTL) mapping and marker-assisted selection for crop improvement: the basic concepts. Euphytica. 2005;142(1-2):169-96.

53. Yang J, Benyamin B, McEvoy BP, Gordon S, Henders AK, Nyholt DR, Madden PA, Heath AC, Martin NG, Montgomery GW, Goddard ME. Common SNPs explain a large proportion of the heritability for human height. Nat Genet. 2010;42(7):565.

54. Débibakas S, Rocher S, Garsmeur O, Toubi L, Roques D, D'Hont A, Hoarau JY Daugrois JH. Prospecting sugarcane resistance to sugarcane yellow leaf virus by genome-wide association. Theor Appl Genet. 2014;127(8):1719-32.

55. Shi J, Li R, Qiu D, Jiang C, Long Y, Morgan C, Bancroft I, Zhao J, Meng J. Unraveling the complex trait of crop yield with quantitative trait loci mapping in Brassica napus. Genetics. 2009;182(3):851-61.

56. Slafer GA. Genetic basis of yield as viewed from a crop physiologist's perspective. Ann Appl Biol. 2003;142(2):117-28.

57. Doyle J. DNA protocols for plants. In: Molecular techniques in taxonomy. Berlin, Heidelberg: Springer; 1991. p. 283-93.

58. Vos P, Hogers R, Bleeker M, Reijans M, Lee TV, Hornes M, Friters A, Pot J, Paleman J, Kuiper M, Zabeau M. AFLP: a new technique for DNA fingerprinting. Nucleic Acids Res. 1995;23(21):4407-14.

59. SAS Institute. SAS/STAT User's guide. Cary: SAS Institute; 2008

60. Nyquist WE, Baker RJ. Estimation of heritability and prediction of selection response in plant populations. Crit Rev Plant Sci. 1991;10(3):235-322.

61. Peakall RO, Smouse PE. GENALEX 6: Genetic analysis in excel. Population genetic software for teaching and research. Mol Ecol Notes. 2006;6(1):288-95. 
62. Powell W, Morgante M, Andre C, Hanafey M, Vogel J, Tingey S, Rafalski A. The comparison of RFLP, RAPD, AFLP and SSR (microsatellite) markers for germplasm analysis. Mol Breed. 1996;2(3):225-38.

63. Shannon CE. A mathematical theory of communication. Bell Syst Tech J. 1948;27(3):379-423.

64. Weising $\mathrm{K}$, Nybom $\mathrm{H}$, Pfenninger M, Wolff $\mathrm{K}$, Kahl G. DNA fingerprinting in plants: principles, methods, and applications: CRC press; 2005.

65. Excoffier L, Smouse PE, Quattro JM. Analysis of molecular variance inferred from metric distances among DNA haplotypes: application to human mitochondrial DNA restriction data. Genetics. 1992;131(2):479-91.

66. Earl DA. STRUCTURE HARVESTER: a website and program for visualizing STRUCTURE output and implementing the Evanno method. Conserv Genet Resour. 2012;4(2):359-61.

\section{Publisher's Note}

Springer Nature remains neutral with regard to jurisdictional claims in published maps and institutional affiliations.

Ready to submit your research? Choose BMC and benefit from:

- fast, convenient online submission

- thorough peer review by experienced researchers in your field

- rapid publication on acceptance

- support for research data, including large and complex data types

- gold Open Access which fosters wider collaboration and increased citations

- maximum visibility for your research: over $100 \mathrm{M}$ website views per year

At BMC, research is always in progress.

Learn more biomedcentral.com/submissions 